\title{
Amino Acids Profile in Mentally Retarded Libyan Children
}

\author{
Nura Nasibe M. , Nuri M. Sh. ${ }^{* *}$,Zienat Kh. \\ *Medical Biochemistry Department, Faculty of Medicine, Garyounis \\ University Benghazi Libya: **Pediatrics Department, Elfateh Children \\ Hospital, Bengazi Libya and *** Applied Medical Chemistry Department, \\ Alexandria University
}

\begin{abstract}
Mental retardation is the most frequently occurring handicap in children. It interferes with learning, social and psychological development. This work was planned, to throw light on mental retardation in Libya, by studying the possible biochemical factors affecting the etiology of this medical and social problem. One hundred and thirty three mentally retarded Libyan children from both sexes were engaged in this study. They were grouped according to etiology of mental retardation into: Down's syndrome (Group I), cerebral palsy (Group II) and other causes rater than DS or CP (group III). Serum levels of amino acids were assayed for all studied groups.

The results obtained revealed that, the level of serum amino acids, serine, glutamine, histidine and arginine were significantly lower in group I than controls. In group II, the level of serum asparagine was statistically higher while the level of glutamine was statistically lower than control. Also, in group II, the levels of asparagine, serine, proline and histidine were statistically higher than group I. In group III, the levels of serine, histidine and arginine were statistically significantly higher than in group I. In group III, significant increase was detected as regards tyrosine, leucine and phenylalanine, while, only glutamine was lower than controls. Low level of serine was noticed to be specific in Down's syndrome in Libyan patients and in other patients as well. So the level of serum serine may be controlled by special diet or special treatment (drugs) to improve their I.Q levels.

In conclusion, to confirm the biochemical results obtained from the present study in Benghazi and on a national level, a larger scale study should be performed on a larger sample size with more facilities to diagnose all types of abnormalities. Also, to evaluate the influence of other risk factors as dietary, cultural and environmental factors on the prevalence and different degrees of mental retardation among infants and children.
\end{abstract}

\section{INTRODUCTION}

Mental retardation (MR) is a universal problem and it is one of the most important causes of human handicap ${ }^{(1)}$. It has been estimated that there are around 500 million moderate to severely disabled persons throughout the world. Two thirds of these are living in developed countries and one-third in the developing countries $^{(2)}$. 
Mental retardation can be caused by any condition which impairs development of the brain before birth, during birth or during childhood. Several hundred causes have been discovered, but in about one-third of the people affected, the cause remains unknown, and can be categorized as follows: ${ }^{(3,4)}$

- Genetic conditions: these result from abnormality of genes inherited from parents, errors when genes combine, or from other disorders of the genes caused during pregnancy.

- Problems during pregnancy: use of alcohol or drugs by the pregnant mother can cause MR. Smoking and other factors as malnutrition, certain environmental contaminants, and illnesses of the mother during pregnancy (such as toxoplasmosis, cytomegalovinus, rubella and syphillis) can increase the risks of M.R.

- Problems at birth: although any birth condition of unusual stress may injure the infant's brain, prematurity and low birth weight predict serious problems more often than any other conditions.

- Problems after birth: childhood diseases such as measles, meningities and encephalities can damage the brain. Lead, mercury and other environmental toxins can cause irreversible damage to the brain and nervous system ${ }^{(3)}$.

\section{PATIENTS \& METHODS}

\section{PATIENTS:}

This study was conducted on 133 mentally retarded children selected from the out patient's clinic of neurology department in El-Fateh children Hospital, Genetic Clinic in El-Sabri Polyclinic, the Assessment and Rehabilitation center, Rehablitation and Training Center in Benghazi-Libya.

The different types of mentally retarded children (with IQ<70), were divided according to disease etiology into three groups:

\section{Group I:}

55-children with mental retardation associated with Down's syndrome diagnosed by the clinical features and proved by chromosomal karyotyping all in which having 47 chromosomes (trisomy 21).

\section{Group II:}

57-children with mental retardation associated with cerebral palsy diagnosed by neurological examination and C.T-scan brain.

\section{Group III:}

55-children with mental retardation due to other causes rather than Down's syndrome or cerebral palsy, this group included:

- 29-children with M.R and epilepsy

- 7-children with different genetic causes of M.R

- 19 children of unknown causes of M.R.

IQ assessment tests were done for all groups at the time of diagnosis.

\section{Control group:}

This group included 37 healthy children with normal I.Q. levels $(>75)$ matched in age and sex with patients groups.

All mentally retarded patients and healthy children were between 3 months and 15 years. Both sexes and patients from different socioeconomic classes were included in this study. Most of the children were 
selected from Benghazi City and from the surrounding small villages.

METHODS:

\section{Sampling:}

A. Blood samples: $5 \mathrm{ml}$ fasting venous blood sample was collected from each child (patients and controls), in plain tube, and allowed to clot for 1-2 hours at room temperature and then the serum was separated by centrifugation at $1000 \mathrm{rpm}$ for 20 minutes and stored at $20^{\circ} \mathrm{C}$ until required for assay.

B. Quantitative determination of serum amino acids:

Concentrations of amino acids were determined by ion exchange column chromatography in serum from fasting blood. Serum was deproteinized by $5 \%$ sulphosalicylic acid $(1: 1, \mathrm{v} / \mathrm{v})^{(\mathbf{5})}$.

The technique for amino acids analysis has been the standard technique where the amino acids are reacted with ninhydrin and then analyzed using an automatic amino acid analyzer biotronic LC 5000 (Eppendorf-Biotronik, Hamburg, Germany) ${ }^{(6)}$.

The level of significance was considered at $\mathrm{P}<0.05$.

\section{RESULTS}

Statistical analysis of the results concerned amino acids revealed that, there is:

1. Amino acids level with significant difference from control (Table 1, Fig 1)

a) Group I had a significant lower mean serum levels of serine
$(28.89 \pm 15.03)$,
$(27.46 \pm 19.71), \quad \begin{array}{r}\text { glutamine } \\ \text { histidine }\end{array}$
$(19.59 \pm 8.15)$
$(24.09 \pm 19.10)$ $(24.09 \pm 19.10)$ than the
corresponding control levels $\{(39.06 \pm 13.34), \quad(37.42 \pm 17.85)$, $(24.16 \pm 8.23)$ and $(36.65 \pm 13.49)\}$ respectively. While group II had a significantly higher mean serum level of asparagine (47.38 \pm 66.94$)$ and lower serum level of glutamine (26.47 \pm 18.49$)$ compared to their matched control serum levels $(10.79 \pm 4.97)$ and $(37.42 \pm 17.85)$. On the other hand Group III, did not show any statistical significant difference in the mean serum amino acids profile compared to the control group.

b) Group II had statistically significant higher mean serum levels of asparagine, serine, proline and histidine compared to group I.

c) Group III had statistically significant higher mean serum levels of serine, histidine and arginine compared to group I, and a significant lower mean level of asparagine compared to group II.

2. Amino acids levels with insignificant difference from control: No significant statistical difference was found in the mean values of aspartic acid, threonine, glutamic acid, glycine, alanine, citrulline, GABA, valine, methionine, isoleucine, leucine, tyrosine, phenylalanine, ornithine, lysine and tryptophan levels between the three studied groups and control group. 
Table (1): Mean Serum values of amino acids (mg/dl) significant different levels among the studied groups.

\begin{tabular}{|c|c|c|c|c|c|}
\hline Amino acids & $\begin{array}{c}\text { Control } \\
\text { group } \\
(n=37)\end{array}$ & $\begin{array}{c}\text { Group I } \\
\text { Down's } \\
\text { syndrome } \\
(\mathrm{n}=48)\end{array}$ & $\begin{array}{c}\text { Group II } \\
\text { Cerebral } \\
\text { palsy } \\
(\mathbf{n}=\mathbf{3 8})\end{array}$ & $\begin{array}{c}\text { Group III } \\
\text { Other causes } \\
\text { of M.R } \\
(n=47)\end{array}$ & $\begin{array}{c}\text { F- } \\
\text { value }\end{array}$ \\
\hline \multicolumn{6}{|l|}{ Asparagine } \\
\hline Range & $4.7-31.9$ & $0.5-16.5$ & $1.5-246.6$ & $2.7-17.4$ & \\
\hline Mean \pm SD & $10.79 \pm 4.97$ & $7.69 \pm 5.89$ & $47.38 \pm 66.94$ & $9.20 \pm 4.20$ & $14.22 *$ \\
\hline $\mathrm{P}$ & & $>0.05$ & $<0.01 \bullet$ & $>0.05$ & \\
\hline P1 & & & $<0.01^{*}$ & $>0.05$ & \\
\hline $\mathrm{P} 2$ & & & & $<0.01 \#$ & \\
\hline \multicolumn{6}{|l|}{ Serine } \\
\hline Range & $24.5-95.8$ & $1.1-77.2$ & $10.4-94.1$ & $3.8-90.3$ & \\
\hline Mean \pm SD & $39.06 \pm 13.34$ & $28.89 \pm 15.03$ & $41.81 \pm 15.01$ & $38.19 \pm 13.95$ & $6.82 * *$ \\
\hline $\mathrm{P}$ & & $<0.01 \bullet$ & $>0.05$ & $>0.05$ & \\
\hline $\mathrm{P} 1$ & & & $<0.01 *$ & $<0.01 *$ & \\
\hline P2 & & & & $>0.05$ & \\
\hline \multicolumn{6}{|l|}{ Glutamine } \\
\hline Range & $3.3-90.0$ & $4.2-59.4$ & $4.1-67.0$ & $2.2-60.4$ & \\
\hline Mean \pm SD & $37.42 \pm 17.85$ & $27.46 \pm 19.71$ & $26.47 \pm 18.49$ & $31.04 \pm 15.93$ & $2.91 *$ \\
\hline $\mathrm{P}$ & & $<0.05$ & $<0.05 \bullet$ & $>0.05$ & \\
\hline P1 & & & $>0.05$ & $>0.05$ & \\
\hline \multicolumn{6}{|l|}{ Histidine } \\
\hline Range & $3.7-56.4$ & $4.0-52.6$ & $10.6-65.3$ & $8.1-45.5$ & \\
\hline Mean \pm SD & $24.16 \pm 8.23$ & $19.59 \pm 8.15$ & $25.94 \pm 8.80$ & $24.57 \pm 6.82$ & $5.40 *$ \\
\hline $\mathrm{P}$ & & $<0.05 \bullet$ & $>0.05$ & $>0.05$ & \\
\hline P1 & & & $<0.05^{*}$ & $<0.05^{*}$ & \\
\hline P2 & & & & $>0.05$ & \\
\hline \multicolumn{6}{|l|}{ Arginine } \\
\hline Range & $8.9-66.9$ & $1.1-82.6$ & $1.2-120.5$ & $1.7-104.6$ & \\
\hline Mean \pm SD & $36.65 \pm 13.49$ & $24.09 \pm 19.10$ & $31.97 \pm 21.18$ & $33.63 \pm 19.94$ & $3.61 *$ \\
\hline $\mathrm{P}$ & & $<0.05 \bullet$ & $>0.05$ & $>0.05$ & \\
\hline $\mathrm{P} 1$ & & & $>0.05$ & $<0.05^{*}$ & \\
\hline $\mathrm{P} 2$ & & & & $>0.05$ & \\
\hline
\end{tabular}

$P^{\bullet}<0.01$ and $<0.05$ : significantly different from control.

$P_{1} *<0.05$ : significantly different from D.S.

$P_{2}^{*}<0.05$ : significantly different from C.P.

$P>0.05:$ Non significant (NS)

$F$ : Fisher exact test

(n): indicates the number of patients 
Fig.(1) The mean Values of Serum amio acids $(\mathrm{mg} / \mathrm{dl})$ that show that statistically significant different levels among the studied groups.

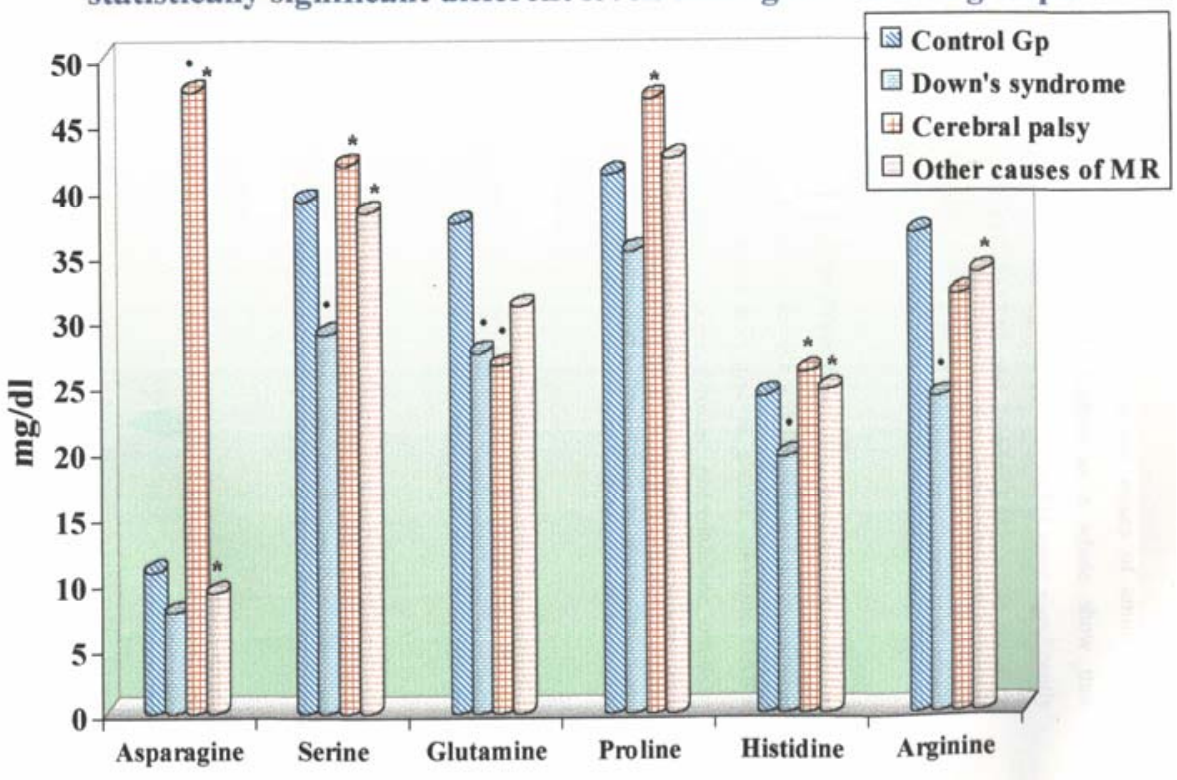

\section{DISCUSSION}

The normal maturation of the brain depends on an adequate supply of glucose, amino acids, lipids and other nutritional factors, and also on appropriate stimulation and continuous interaction with the environment ${ }^{(7)}$.

In the present study, the mean value of serum amino acid levels in Down's syndrome Libyan children group showed a significantly low levels of serine, glutamine, histidine and arginine.

The most interesting finding in this work is the low level of the mean value of serum serine in patients with Down's syndrome compared with controls. This is because serine may have a role in mental retardation.
Similar findings were reported by Libyan workers in $(1993)^{(\mathbf{8})}$, and by Lejeune, et al in $(1992)^{(9)}$, which was proved also by other workers in different parts of the world ${ }^{(\mathbf{1 0 , 1 1})}$. Low serine level is considered a specific and characteristic amino acid's abnormality in patients with Down's syndrome, and not in patients with other causes of mental retardation ${ }^{(9,10)}$.

The decreased serine level in the sera of patients with Down's syndrome could be of substantial evidence that there is a defect in serine trans-hydroxymethylase, converting glycine to serine in the brain $^{(\mathbf{1 2})}$. Besides, it has been stated that glycine (one of the putative neurotransmitters of the brain) has binding sites in the brain stem and spinal cord ${ }^{(\mathbf{1 3})}$. In additions, the defect 
in glycine metabolism was explained to be due to absence of glycine oxidase $^{(\mathbf{1 4})}$, serine being a precursor of choline, acetyl choline and cephalins of brain and nervous system, seems to be an important amino acid in the structural lipids in the brain ${ }^{(\mathbf{8})}$.

The relation between amino acids metabolism and mental retardation had attracted the attention of many authors. Thus, a significant decrease in plasma homocysteine level in Down's syndrome was observed by some authors ${ }^{(15,16)}$. An increased serum levels of glycine ${ }^{(8)}$, lysine $e^{(\mathbf{9 , 1 0})}$ and leucine, phenylalanine, isoleucine, cystine, were found in Down's syndrome patients ${ }^{(\mathbf{1 7})}$, and other different causes of mental retardation ${ }^{(\mathbf{1 8 )}}$. Moreover, serum glycine has been found to be increased in cerebral palsy and in mental retardation $^{(\mathbf{1 9})}$.

A significant decrease in plasma homocysteine level in Down's syndrome was observed by some authors $^{(15)}$. An increased serum levels of glycine ${ }^{(8)}$, lysine $^{(9)}$ and leucine, phenylalanine, isoleucine, cystine, were found in Down's syndrome patients $^{(17)}$. Moreover, serum glycine has been found to be increased in cerebral palsy $^{(\mathbf{1 9 )}}$.

Tryptophan and tyrosine were decreased in patients with Down's syndrome compared with matched controls $^{(17)}$.

The study of Lejeune and his colleagues in (1992), ${ }^{(9)}$ showed that the concentration of serum cysteine and lysine were increased in patients with Down's syndrome and that the concentration of serum serine was decreased when compared with controls. Our findings confirmed
Lejeune's ${ }^{(9)}$ results only as regards the decreased serum concentration of serine in Down's syndrome.

In the present study, only the group of patients with cerebral palsy was found to have a statistically significant increased serum level of asparagine and decreased level of glutamine as compared to controls, these findings suggest that increased asparagine level might play an important role in causing mental retardation.

Increased serum asparagine level in children with mental retardation and in Down's syndrome was previously reported $^{(\mathbf{2 0 , 2 1})}$.

Some other authors reported a hyperglycinemia in children with cerebral palsy ${ }^{(22)}$. While others had reported increased serum arginine level in the same patients ${ }^{(23)}$. These alterations of serum amino acids in children with cerebral palsy, led some workers to use amino acids preparations in the treatment of this group of children, which is important for their motor and mental functions. These findings suggest that any child presented with unknown cause of cerebral palsy could be related to amino acid disorders and serum amino acid screening is an advisable investigation in these cases ${ }^{(\mathbf{1 6 , 2 4 )}}$.

The mean serum glutamine level was found to be significantly low in patients of all the groups studied in the present work in comparison to controls. Similar results of decreased serum glutamine level in Down's syndrome, and in non-down's syndrome mentally retarded children were also reported ${ }^{(21)}$. Some other workers found a significant deficit of glutamate and GABA in the Down's 
syndrome children when compared to matched control ${ }^{(25)}$. Also studies of amino acids concentrations done during epileptic seizure suggests a generalized lowering of GABA, asparatic acid, glutamic acid and taurine $^{(\mathbf{2 6})}$. The low level of serum glutamine in Down's syndrome was discovered as early as $1949,{ }^{(27)}$ since that time many workers, evaluated the effect of glutamic acid treatment in the intellegence of patients with Down's syndrome. Zimmerman ${ }^{(27)}$ showed some rise in the intellegence quotient after glutamic acid treatment in his group of patients.

Other workers reported that, the addition of amino acids such as methionine, tyrosine and tryptophan, to the diet of children with Down's syndrome, may improve the mental function rather than the glutamic acid treatment ${ }^{(28)}$. In the USA, the Scientific Advisory Committee of Trisomy 21 Research Foundation recommended the use of special diet formula containing many amino acids for patients with Down's syndrome to improve their mental function ${ }^{(\mathbf{2 9})}$.

In the present study, proline level showed a significantly increased level in cerebral palsy group compared with other groups of mental retardation. In addition histidine showed a significantly decreased level, only in patients with Down's syndrome.

In cerebral palsy children, some authors found an increased serum arginine level. These authors reported that increased arginine was due to arginase deficiency, so increased arginine level causes severe mental retardation and spastic quadriplegia accompanied by tonic seizures ${ }^{(22)}$.
However, no information has been reported regarding the nature and magnitude of the problem of mental retardation in Libya. Such information would be necessary in order to formulate public policy for services of the mentally retarded children.

In this study an attempt was made to provide information regarding the nature and the extent of the problem of mental retardation in Libya by carrying out a prospective evaluation of all the patients of mental retardation who were referred to the clinical neurology and genetic clinic departments.

\section{REFERENCES}

1. Wald I. Prevention of mental handicap genetic aspects. Garyounis Med J 1980; 3: 69-72.

2. WHO. Seventh Report on "World Health Situation" Global Analysis, World Health Organization, Geneva, 1987.

3. American Association on Mental retardation. Definition, classification and systems of supports $9^{\text {th }}$ ed. Washington, DC. 1992

4. Mclaren $J$ and Bryson SE. Review of recent epidemiological studies of mental retardation. Am J Ment Retard 1987; 92(2): 243252.

5. Gobien N, Schlebusch H. and Knopp. M. Alterssperzif sche und geschlechtssp. Klin Padiatr 1990; 417-421.

6. Peter Schadewaldt. Klinische Biochemie. Auf'm Hennekamp 65. D-40225 Düsseldrof. Germany._schadewa@uniduesseldorf.de. 
7. Edward Bittar and Neville Bittar. The biological basis. Vol (5). Academic Press. London. 1969; 111-122.

8. Ziu M, MN Nura, Nossair M, Abulaziz F. Hyperglycinemia and amino transferase activity in Down's syndrome in Libya. EMJ 1993; 10(2): 67-70.

9. Lejeune J, Rethore Mo, de Biois MC, Naffah J, Mircher C, Rabier-D. Amino acids and trisomy 21. Ann Genet 1992; 35(1): 8-13.

10. Heggary HJ, Ball R, Smith M, Henderson MJ. Amino acid profile in Down's syndrome. Arch Disease Child 1996; 74: 347-349.

11. Mircher C, Salabella A, Pecters MA, Rabier D, Parvy P. Variation of amino acids in relation to age in Down syndrome subjects. Arch Pediatr 1997; 4(11): 1093-9.

12. Montogmry R, Robert LD, Thomas WC, Arthur AS, Biochemistry: A case oriented approach $4^{\text {th }}$ ed. C.V. Mosby Company st louis Toronto, Canda. 482, 1983; 656.

13. Defeulis FV, Can the binding of GABA, glycine and alanine to synaptic receptors be determined in the presence of a physiological concentration of $\mathrm{Na}$. Experienta 1978; 1314-1315.

14. Gerritsen $T$, Kaveggia $E$ and Waisnan HA. A new type of idiopathic hyperglycinemia with hypooxaluria. Pediatr 1965; 36: 882.

15. Chadefaux B, Ceballos J, Hamet $M$, Coude $M$ and Dallard D. Is absence of a theroma in Down's syndrome due to decreased homocysteine levels? Lancet 1988; 2(8613): 741.

16. Folbergrova J, Haugvicova $R$, Mares P. Behavioral and metabolic changes in immature rats during seizures induced by homocytic acid. Exp Neurol 2000; 161(1): 336-45.

17. Watkins SE, Thomas DE, Clifford M, Tidmarch SF, Sweeney AE, Ahsing E. Plasma amino acids in patients with dementia and in subjects with Down's syndrome. J Ment Defic Res 1989; 33(pt2): 159-66.

18. Watkins SE, Clifford ME, Tidmarsh SF and Shaw DM. Plasma amino acids, Down's syndrome and dementia. Brith J Psych 1986; 148: 339-340.

19. Balcis B, Firat T. Corneal opacity, mental retardation, microcephaly and generalized muscular spasticity Clin Genet 1974; 5(1): 36-9.

20. Turova NF, Ermolina LA, Baryshnikov VA. Characteristics of the amino acid spectrum of the blood of children with intellectual deficiency Zh-Nerro Patol Psikh 1986; 86(3): 372-5.

21. Risser-D, Lubec G, Gairns N, Herrera M. Excitatory amino acids and monoamines is parahippocampal gyrus and frontal corticol pole of adults with Down's syndrome. Life Sci 1997; 60(15): 1231-7.

22. Sakiyama $T$, Nakabayashi $H$, Shimizu H, Koudo W. A successful trial of enzyme replacement therapy in a case of 
argininemia. Tonoku J Exp Med 1984; 142(3): 239-48.

23. Prasad AN, Breen JC, Anpola MG, Rosman NP. Argininemia: a treatable genetic cause of progressive spastic diplegia stimulating cerebral palsy. J Child Neurol 1997; 12(2): 301-9.

24. Papazian O, Alfonso I. Cerebral palsy therapy. Rev Neurol 1997; 25(141): 728-39.

25. Reynolds GP, Warner CE. Amino acid neurotransmitter deficits in adult Down's syndrome brain tissue. Neurosci Lett 1988; 94(1-2): 224-7.

26. Gelder NM, Sherwin AL, Rosmussen T. Amino acid content of epileptogenic human brain. Brain Research 1972; 40: 385-393.

27. Zimmerman F.T, Burgemeister B.B., Putnam TJ. Effect of glutamic acid on the intelligence of patients with Monogolism. Arch Neurolog Psych 1949; 61: 275-287.

28. Information-Down's syndrome. www.accessnablt.com. au/handbook/downsyn.

29. Lawrence G. Leichtman. Genetics and disabilities. Diagnostic care center. leicht@exis.net http//www.tri21.org/leicht. 1996. 


\section{دراسة بيو كيميائية للأطفال الليبيين المتخفين عقلياً}

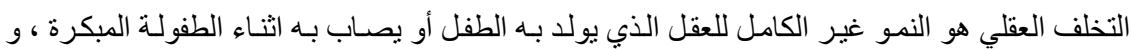

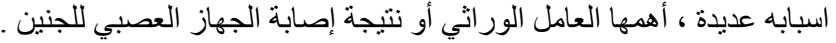

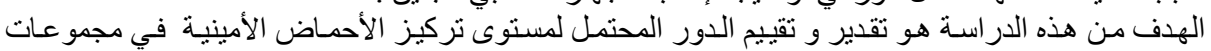

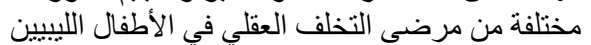

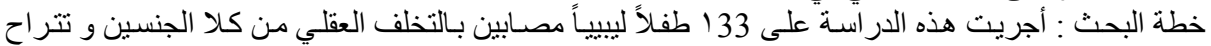

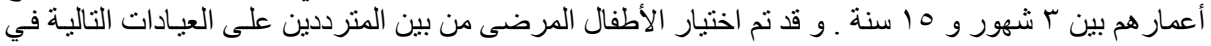
مدينة بنغازي : أعمار بين

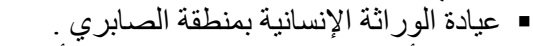

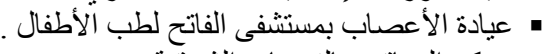

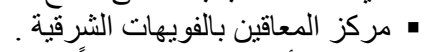

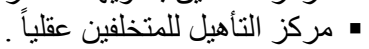

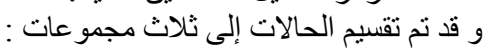

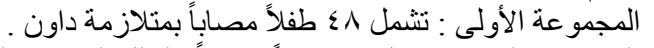

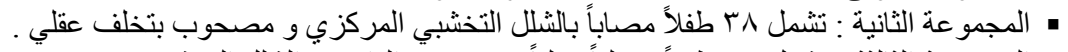

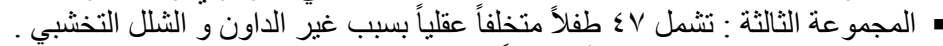

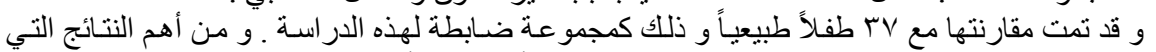

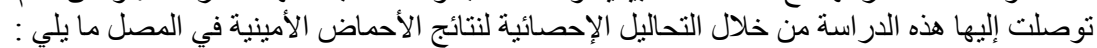

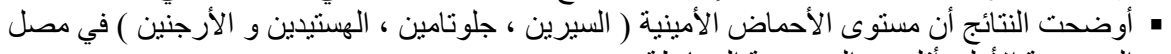

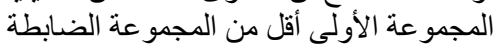

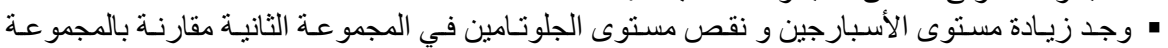
الضابطة . وهان.

• وجد أن مستوى الأسبارجين و الهيستيدين و الأرجنين أعلى في المجموعـة الثالثـة مقارنـة بالمجموعـة

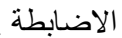

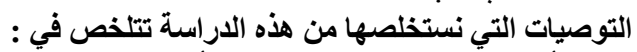

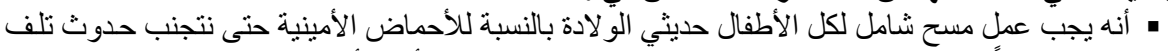

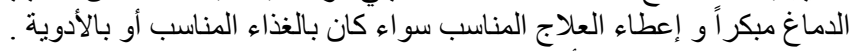

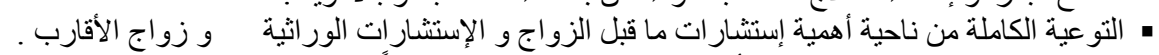

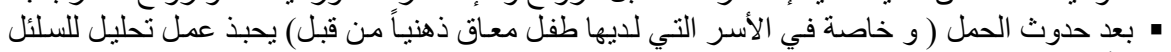

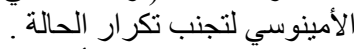
• يجب إجراء المزيد من الأبحاث في ليبيا خاصة في هذه الحالات . 